\title{
Liquid-phase hydrogenation of bio-refined succinic acid to 1,4-butanediol using bimetallic catalysts
}

\author{
Pabitra Kumar Baidya', Ujjaini Sarkar ${ }^{1 *}$, Raffaela Villa ${ }^{2}$ and Suvra Sadhukhan ${ }^{3}$
}

\begin{abstract}
Development of a Crotalaria juncea based biorefinery produce large quantity of waste glycerol after trans-esterification of the juncea seeds. This glycerol, after purification, is used as a substrate for producing succinic acid on a microbial route. Hydrogenation of this bio-refined succinic acid is carried out under high pressure in order to produce 1,4butanediol (BDO) using a batch slurry reactor with cobalt supported ruthenium bimetallic catalysts, synthesized inhouse. It is demonstrated that, using small amounts of ruthenium to cobalt increases the overall hydrogenation activity for the production of 1,4-butanediol. Hydrogenation reactions are carried out at various operating temperatures and pressures along with changes in the mixing ratios of ruthenium chloride and cobalt chloride hexahydrate, which are used to synthesize the catalyst. The Ru-Co bimetallic catalysts are characterized by XRD, FE-SEM and TGA. Concentrations of the hydrogenation product are analyzed using Gas chromatography-Mass spectrometry (GC-MS). Statistical analysis of the overall hydrogenation process is performed using a Box-Behnken Design (BBD).
\end{abstract}

Keywords: 1,4-Butanediol, Biorefinery, Succinic acid, Hydrogenation, Ru-Co bimetallic catalyst

\section{Background}

Succinic acid is reported many times as a potential platform chemical produced in bio-refineries $[1,2]$. This dicarboxylic acid is an intermediate of the tricarboxylic acid (TCA) cycle and the same could replace the maleic anhydride produced from oil as a $\mathrm{C} 4$ building-block chemical. Conversion of succinic acid (SA) to high-value compounds has become a state-of-the-art research topic in the last few years resulting from its large-scale microbial productions utilizing waste glycerol as the primary substrate. Many research groups from all over the world have reported conversion of bio-refined succinic acid into various value-added chemicals. Production of succinic acid on a microbial route has been investigated with many strains in the last decade with final concentrations as high as $146 \mathrm{gl}^{-1}$ [3-6]. However, purification of succinic acid is very expensive $[5,7,8]$. The purification costs could be as high as $50-80 \%$ of the total process costs.

\footnotetext{
* Correspondence: ujjaini.sarkar@jadavpuruniversity.in;

abhi_nandan47@rediffmail.com

'Department of Chemical Engineering, Jadavpur University, Kolkata 700032, India

Full list of author information is available at the end of the article
}

As an intermediate, succinic acid could be utilized to produce some derivatives following suitable catalytic pathways in order to make the bio-refinery a profitable unit. Researchers have shown that the bio-based succinic acid can be converted to 1,4-butanediol by catalytic hydrogenation process under high pressure $[9,10]$. Succinic acid can also be transformed to other useful chemicals like gamma-butyrolactone (GBL) and tetrahydrofuran (THF) by the hydrogenation process using different metal containing catalysts [11].

1,4-butanediol (BDO) is a well-known solvent in many industries, widely used in medical, chemical, textile, papermaking, automobile and in chemical industries producing goods of daily-use [12]. In organic chemistry, 1,4-butanediol is also used for the synthesis of gamma-butyrolactone, which has a great medicinal value in the pharmaceutical industry. In addition, it is also used as a key intermediate for producing polybutylene succinate (PBS) and polybutylene terephthalate (PBT). In presence of selective noble metal catalysts, it gets converted to the important solvent tetrahydrofuran by hydrogenation under high temperature.

(c) The Author(s). 2019 Open Access This article is distributed under the terms of the Creative Commons Attribution 4.0 International License (http://creativecommons.org/licenses/by/4.0/), which permits unrestricted use, distribution, and reproduction in any medium, provided you give appropriate credit to the original author(s) and the source, provide a link to the Creative Commons license, and indicate if changes were made. The Creative Commons Public Domain Dedication waiver (http://creativecommons.org/publicdomain/zero/1.0/) applies to the data made available in this article, unless otherwise stated. 
Hydrogenation of succinic acid to 1,4-butanediol occurs via a two-step process: (i) succinic acid is first transformed into gamma-butyrolactone by hydrogenation and then (ii) 1,4-butanediol or tetrahydrofuran is formed through successive hydrogenation of gamma-butyrolactone with selective metal catalysts [13-15]. Transition element supported noble metals are the most effective catalysts in hydrogenation of succinic acid. Based on their selectivity, Platinum (Pt), Palladium (Pd), Ruthenium (Ru) and Rhenium (Re) containing catalysts are found to be very efficient in hydrogenation of succinic acid to gammabutyrolactone and other chemicals [16]. For the production of 1,4-butanediol, however, a very strong catalyst activity for hydrogenation of carbonyl group is also required. Therefore, it is important to find a suitable noble metal catalyst that has both cyclization activity $(\mathrm{SA} \rightarrow \mathrm{GBL})$ and oxidative-hydrogenation activity (GBL $\rightarrow 1,4-\mathrm{BDO})$ in the hydrogenation of succinic acid to 1,4-butanediol [17-19]. It is known that Rhenium ( $\mathrm{Re}$ ) can completely reduce both carboxyl and carbonyl groups at a time, leading to further hydrogenation of gamma-butyrolactone. On the other hand, rhenium catalyst can be a possible prospect for selective production of 1,4-butanediol in the hydrogenation of succinic acid [18]. However, due to a high price of Rhenium, other noble metals are examined as a promising catalyst for the hydrogenation process. Ruthenium ( $\mathrm{Ru})$ promoted Cobalt (Co) catalyst is found to be very effective in the hydrogenation of succinic acid [20-22].

This piece of research is only a part of a bio-refinery where Crotalaria juncea is used as the major feedstock. First oil is extracted from the Crotalaria juncea seeds [23], which then gets trans-esterified using traditional and natural catalysts to produce a bio-diesel along with a huge quantity of waste glycerol [24]. The waste glycerol is then purified using sequential desalination [25] and further utilized as the primary substrate for producing bio succinic acid using E.Coli during microbial fermentation [26]. In this particular work, a number of Ru-Co bimetallic catalysts are synthesized with varying contents of $\mathrm{Ru}$. These catalysts are then physically characterized using XRD, FE-SEM and TG/DTA and applied to the liquid-phase hydrogenation of succinic acid, already bio-refined, in order to produce 1,4-butanediol in a batch slurry reactor [27]. The effect of metal content on the physicochemical properties of the catalysts is investigated. The yield of 1,4-butanediol is optimized using Response Surface Methodology, using Design Expert software version 9.0.3.1. (Make: StatEase Inc., USA).

\section{Methods}

\section{Preparation of catalyst}

Ruthenium-Cobalt bimetallic catalysts with varying compositions are prepared for hydrogenation of succinic acid. Cobalt chloride hexa-hydrate $\left[\mathrm{Cl}_{2} \mathrm{CoH}_{12} \mathrm{O}_{6}, \mathrm{ACS}\right.$ reagent, 98\%, Sigma Aldrich, USA], ruthenium chloride $\left[\mathrm{RuCl}_{3} \cdot \mathrm{xH}_{2} \mathrm{O}\right.$, Aldrich, USA, $\mathrm{Ru}$ content 45-55\%] and 1,4-dioxane (solvent) [Anhydrous, 99.8\%, Sigma-Aldrich, Germany] are used for synthesizing the catalyst. HPLC grade water [Merck, India] and ammonium carbonate [ACS reagent, Merck, India] are purchased from Merck, India. Initially, calculated amounts of cobalt chloride hexahydrate and ruthenium chloride are mixed together in the ratio of $1-3 \%$ of ruthenium to cobalt and then dissolved in $20 \mathrm{ml}$ HPLC grade water to which $10 \%(w / \mathrm{w})$ of ammonium carbonate solution is added with constant stirring $(500 \mathrm{rpm})$ until a $\mathrm{pH}$ of 8 is reached. The precipitated carbonates are then filtered with Whatman filter paper and washed several times with distilled water in order to obtain an alkali-free precipitate. After drying the metal carbonates at $110{ }^{\circ} \mathrm{C}$ in presence of air for $10 \mathrm{~h}$, calcination is carried out at $700{ }^{\circ} \mathrm{C}$ with a ramp rate of $3{ }^{\circ} \mathrm{C} / \mathrm{min}$ ) in presence of air for $12 \mathrm{~h}$ in a muffle furnace in order to decompose the metal carbonates. The residues are then reduced in a high pressure autoclave (Make: Parr Instrument Co., USA; Model: Series 4560 Mini Reactors, $600 \mathrm{~mL}$ ) under $45 \mathrm{bar}$ hydrogen atmosphere at $250{ }^{\circ} \mathrm{C}$ for $12 \mathrm{~h}$. The autoclave is fitted with a stirrer, cooling coil, gas inlet/ outlet and liquid sampling system, automatic temperature controller, speed controller for agitation, safety rupture disc, high temperature cut-off and pressure recording facility. This is first purged with $\mathrm{N}_{2}$ (Linde, India; >99.99\%). $\mathrm{A} \mathrm{H}_{2}$ gas cylinder (Make: Linde, India; Purity: >99.99\%) is used, along with a constant pressure regulator (Make: Concoa, Sweden), to supply $\mathrm{H}_{2}$ at a flow rate of $80 \mathrm{~mL} / \mathrm{min}$. Initial temperature of the reduction process is set at $100{ }^{\circ} \mathrm{C}$ with a set of step increases of $50{ }^{\circ} \mathrm{C} / 20 \mathrm{~min}$ until a final temperature of $250{ }^{\circ} \mathrm{C}$ is reached. Initial pressure is set at 20 bar and then increased to 45 bar after $1 \mathrm{~h}$. The reduced catalysts are then stored in a glove-box in $\operatorname{Ar}$ (>99.99\%, Linde, India) to avoid oxidation.

\section{Characterisation of catalyst}

Physical characterization of the ruthenium promoted cobalt catalysts with varying composition is carried out using:

a. X-Ray Diffraction (XRD): Composition and crystalline states of the ruthenium-cobalt bimetallic catalysts (Ru-Co) are examined by XRD (X-ray diffraction) measurements [28]. XRD patterns of the samples are obtained in the scanning angle $(2 \theta)$ range of $1^{\circ}-1185^{\circ}$ on a Rigaku X-Ray Diffractometer (Model: Ultima - III) instrument using $\mathrm{Cu}-\mathrm{K}$ radiation $(\lambda=1541 \AA)$ operated at $40 \mathrm{kV}$ and $30 \mathrm{~mA}$.

b. Field Emission Scanning Electron Microscopy (FESEM) and EDX (Energy-Dispersive X-Ray) based analysis: A Field Emission Scanning Electron 
Microscope [Make: JEOL; Model: JSM 7610F] [29-31] is used in order to identify the morphology of the catalysts. EDX analysis is carried out for identifying the elements present in the catalysts with their relative weight and atomic percentages.

c. Thermo-Gravimetry and Differential Thermal Analysis (TG/DTA): Thermal stability of these catalysts is performed using Thermo-Gravimetry (TG) and Differential Thermal Analysis (DTA) (TGA) $[26,28]$ with a TG/DTA [Make: PerkinElmer, Singapore; Model: Pyris Diamond] analyser. About $10 \mathrm{mg}$ of the sample is loaded onto a Platinum crucible with alpha alumina powder being used as the reference. A steady $\mathrm{N}_{2}$ flow rate of $150 \mathrm{ml} / \mathrm{min}$ is maintained with a specific temperature programme (ramp at $10^{\circ} \mathrm{C} / \mathrm{min}$ from room temperature $\left(30^{\circ} \mathrm{C}\right.$ ) to $100^{\circ} \mathrm{C}$, held for $20 \mathrm{~min}$ and then ramp at $15^{\circ} \mathrm{C} /$ min) till a final temperature of $900^{\circ} \mathrm{C}$ is reached.

Preparation of bio-refined succinic acid for hydrogenation In this research work, initially, oil is extracted from Crotalaria juncea seeds using standard Soxhlet apparatus [23] and later trans-esterified to produce biodiesel [24]. Crude glycerol is purified after separation, employing various physico-chemical treatments. The purification process is designed on the basis of acidification, neutralization, solvent extraction, adsorption and finally pressure filtration through membrane [25]. This purified glycerol is used as the primary carbon source to produce succinic acid using single culture of Escherichia coli. A number of batch fermentation experiments are conducted at $37^{\circ} \mathrm{C}$ and $120 \mathrm{rpm}$ in mineral salts medium in a shaker incubator for $72 \mathrm{~h}$ with various glycerol concentrations to observe the cell growth and substrate utilization rate. Succinic acid is analysed using a High-Performance Liquid Chromatography (HPLC) system (Make: Waters, Model: Series 200) equipped with a C18 column. The analysis is performed using $1 \%$ acetonitrile and $20 \mathrm{mM} \mathrm{K}_{2} \mathrm{HPO}_{4}$ as the mobile phase and peaks are monitored by UV detector (wavelength: $210 \mathrm{~nm}$ ). The concentrations of succinic acid in the unknown solutions are estimated using standard curves prepared by plotting peak areas versus known concentrations of succinic acid samples. The entire process is optimized for a maximum production of succinic acid [26].

\section{High pressure hydrogenation of succinic acid}

Hydrogenation experiment is initiated with 21.96 g succinic acid seeded with a $6.25 \mathrm{~g} \mathrm{Ru}-\mathrm{Co}$ catalyst in a high pressure autoclave (Make: Parr Instrument Co., USA; Capacity: $6 \times 10^{-4} \mathrm{~m}^{3}$; Material: Stainless Steel). The total reaction volume is made up to $100 \mathrm{ml}$ using a mixture of 1,4-dioxane and water (solvent) in a ratio of 15:1. Before the reaction starts, the reactor is purged with
Table 1 Experimental ranges of the independent variables for RSM study

\begin{tabular}{lllll}
\hline Variable & Unit & Coded variable & Low & High \\
\hline Catalyst Concentration & $\%$ Ru-Co & A & 1 & 3 \\
Temperature & ${ }^{\circ} \mathrm{C}$ & $\mathrm{B}$ & 180 & 250 \\
Pressure & $\mathrm{Bar}$ & $\mathrm{C}$ & 45 & 75 \\
\hline
\end{tabular}

nitrogen to remove air from the reactor thereby avoiding the risk of hazards. The reactions are carried out at a temperature of $250^{\circ} \mathrm{C}$ and a total pressure of 70 bar for investigating the activity of $\mathrm{Ru}-\mathrm{Co}$ catalyst using bio-refined succinic acid as the substrate. Initial temperature and pressure are set at $100^{\circ} \mathrm{C}$ and 50 bar respectively. As time elapsed, the temperature is increased to $150^{\circ} \mathrm{C}, 200^{\circ}$ $\mathrm{C}$ and finally $250^{\circ} \mathrm{C}$, where the temperature ramp is

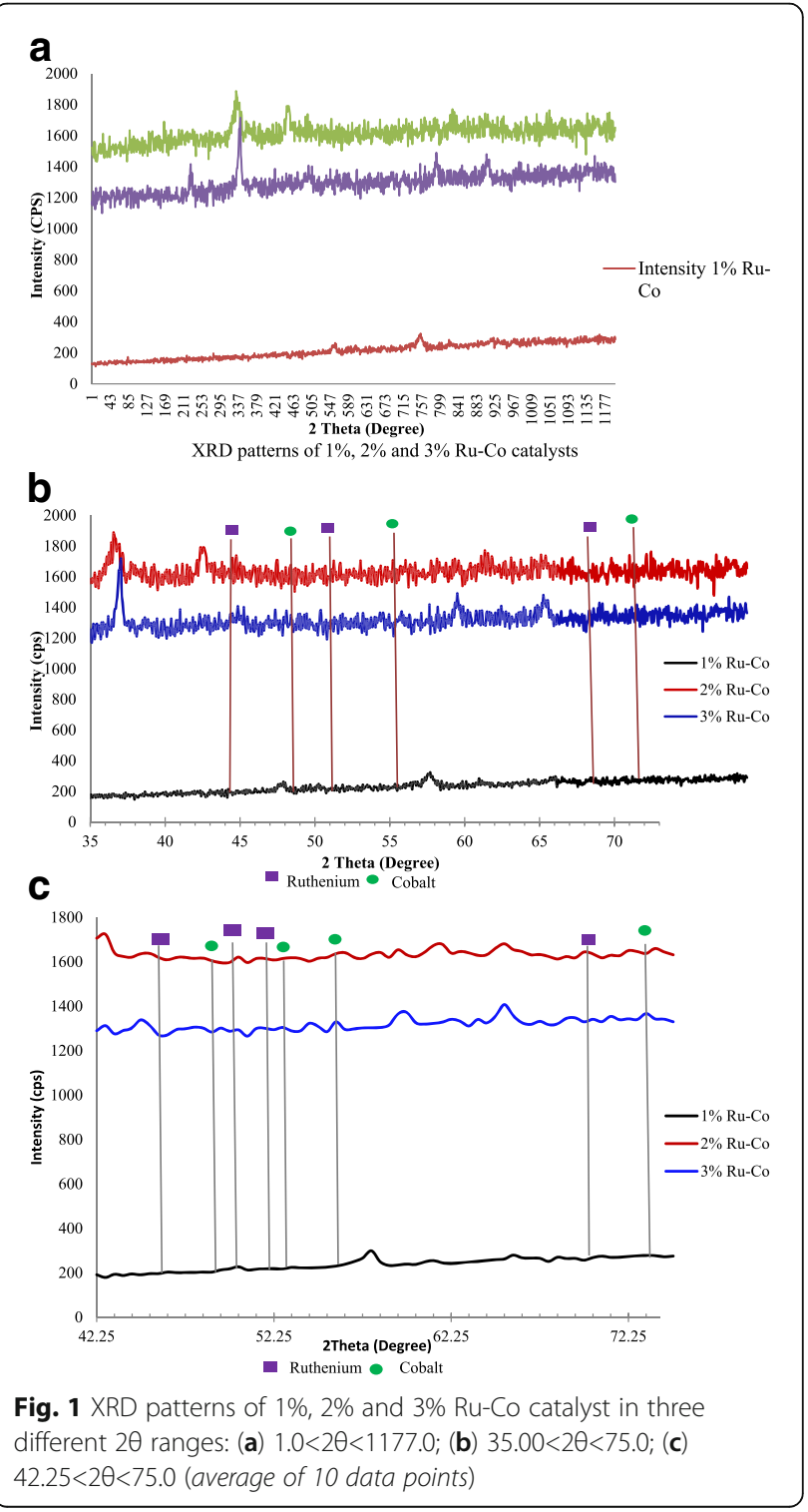


maintained at $50^{\circ} \mathrm{C} / 20 \mathrm{~min}$ time interval. With the increase in temperature, pressure also increases from 50 bar to 70 bar. The entire reaction is carried out for $6 \mathrm{~h}$ under constant agitation at $450 \mathrm{rpm}$ stirrer speed. The product is then recovered by filtration.

\section{Analysis of 1,4-butanediol using GC/MS}

A Gas Chromatograph (Make: Thermo Scientific, USA; Model: Trace GC Ultra) with a TR-Wax MS column (Make: Thermo Scientific, USA), $30 \mathrm{~m}$ long, $0.25 \mathrm{~mm}$ ID, with a film thickness of $0.25 \mu \mathrm{m}$, equipped with an EI (Electron Impact) detector (Make: Thermo Scientific; Model: Polaris Q) is used to estimate 1,4-butanediol, produced after hydrogenation of succinic acid. Helium gas, with a flow rate of $0.3 \mathrm{ml} / \mathrm{min}$ and a linear velocity of $10 \mathrm{ml} \mathrm{s}^{-1}$, is used as carrier gas. The split ratio is kept at 1:20. The sample is purified by filtration using a syringe filter (MILLEX; GV; $0.22 \mu \mathrm{M}$ ) and $1 \mu \mathrm{L}$ of sample is injected for analysis. The initial temperature of the oven is set at $70^{\circ} \mathrm{C}$ for a hold-up time of $2 \mathrm{~min}$. In the first ramp, the oven is heated at a rate of $10^{\circ} \mathrm{Cmin}^{-1}$ to reach a temperature of $260^{\circ} \mathrm{C}$ with a holding time of 10 min. The ultimate oven temperature is set at $350^{\circ} \mathrm{C}$. 70 $\mathrm{eV}$ electron impact ionization (EI) mass spectra are collected from the runs and the results analysed using $\mathrm{GC} /$ MS Xcalibur software (Make: Thermo Scientific; Version:3.1). The relevant chromatograms for the standard and the 1,4 BDO samples are given in Additional file 1: Figure S1 and Additional file 2: Figure S2).

\section{Statistical analysis}

The yield of 1,4-butanediol is then statistically analyzed and optimized by Response Surface Methodology (RSM) using a Box-Behnken Design (BBD) [32, 33]. The optimization process is carried out by varying three factors viz. catalyst concentration, temperature and pressure. Based on the three-level factorial values generated by the Design Expert software, (Make: Stat-Ease Inc., USA; Version: 9.0.3.1), two extreme points (highest and lowest) are used for each factor (1.0 and $3.0 \mathrm{wt} \%$ for catalyst concentration, $180^{\circ} \mathrm{C}$ and $250^{\circ} \mathrm{C}$ for temperature and $45 \mathrm{bar}$ and $70 \mathrm{bar}$ for pressure).



Fig. 2 FE-SEM images of (a) 1\% Ru-Co, (c) 2\% Ru-Co and (e) 3\% Ru-Co bimetallic catalyst. Corresponding EDX spectra for (a), (c) and (e) are in (b), (d) and (f), respectively 
Ranges of the variables are given in Table 1 . The experimental runs are performed based on seventeen different combinations of the coded variables. The experimental data are then analysed and a second-order quadratic polynomial fit [see eq. (1)] is obtained. It describes the relationship between the predicted response variable (Yield of 1,4-butanediol) and the independent variables of the process (catalyst concentration, temperature and pressure).

$$
Y=\beta_{0}+\sum_{i=1}^{N} \beta_{i} \times X_{i}+\sum_{i=1}^{N} \beta_{i i} X_{i}^{2}+\sum_{i=1}^{N} \sum_{j>1}^{N} \beta_{i j} \times X_{i} X_{j}
$$

Where, $Y$ is the response (Yield of 1,4-butanediol), $X_{i}, X_{j}$ are the coded variables, $\beta_{0}$ is the intercept, $\beta_{i}$ is the linear, $\beta_{i i}$ is the quadratic and $\beta_{i j}$ is the interaction coefficients. $N$ is the number of factors considered in the experiment. The coefficients of determination $\left(R^{2}\right)$ and analysis of variance (ANOVA) justify the goodness of fit. Contour plots for the independent variables are developed from the experimental data obtained, following BBD procedures.

\section{Results}

\section{Catalyst characterization}

$X R D$

The X-Ray Diffraction (XRD) patterns of the reduced catalysts (both monometallic and bimetallic) are shown in Fig. 1 [(a), (b), (c)] in three different regimes of $2 \theta$. The same show that $\mathrm{Co}$ and Ru exist predominantly in the metallic state. The monometallic Co displayed the characteristic peaks of cubic $\mathrm{Co}_{3} \mathrm{O}_{4}\left(\mathrm{CoO} \cdot \mathrm{Co}_{2} \mathrm{O}_{3}\right)$, while the pattern of the monometallic Ru showed the characteristic peaks of $\mathrm{Ru}_{2} \mathrm{O}_{3}$ [Fig. 1 (c); refer XRD_Card_of_Ru_and_Co.pdf in the Additional file 3]. The presence of carbonates of $\mathrm{Co}^{+2}$ and $\mathrm{Ru}^{+3}$ are also observed. Following Scherrer equation ${ }^{11}$ the particle size of cobalt crystallite is found to be in the range of $30-35 \mathrm{~nm}$, whereas that of ruthenium is in the range of $22-25 \mathrm{~nm}$. These values are determined from the $2 \theta$ values obtained from the XRD spectrum. No alloy formation is evident as $2 \theta$ values observed correspond to those of standard Co and Ru metal [Ru: $44.88^{\circ}, 49.36^{\circ}$, $68.92^{\circ}$ and $\left.C o: 48.80^{\circ}, 55.84^{\circ}, 74.36^{\circ}\right]$.

Table 2 EDX analysis of different Ru-Co bimetallic catalysts

\begin{tabular}{|c|c|c|c|c|c|c|}
\hline \multirow[t]{2}{*}{ Element } & \multicolumn{2}{|l|}{$1 \%$ Ru-Co } & \multicolumn{2}{|l|}{$2 \%$ Ru-Co } & \multicolumn{2}{|l|}{$3 \% \mathrm{Ru}$ Co } \\
\hline & Weight\% & $\overline{\text { Atomic} \%}$ & Weight\% & $\overline{\text { Atomic } \%}$ & Weight\% & $\overline{\text { Atomic } \%}$ \\
\hline C & 14.91 & 40.17 & 10.92 & 23.96 & 9.96 & 24.06 \\
\hline $\mathrm{O}$ & 10.69 & 21.63 & 31.96 & 52.62 & 26.38 & 47.82 \\
\hline Co & 67.46 & 37.04 & 50.21 & 22.44 & 53.73 & 26.44 \\
\hline $\mathrm{Ru}$ & 0.13 & 0.04 & 0.46 & 0.12 & 1.60 & 0.46 \\
\hline $\mathrm{Au}$ & 6.81 & 1.12 & 6.44 & 0.86 & 8.32 & 1.23 \\
\hline
\end{tabular}

After calcination The intensity of the $\mathrm{Co}_{3} \mathrm{O}_{4}$ diffractions decrease for the reduced $\mathrm{Ru}-\mathrm{Co}$ samples in the order: $\mathrm{Ru}_{0.1} \mathrm{Co}_{0.9}<\mathrm{Ru}_{0.3} \mathrm{Co}_{0.7}<\mathrm{Ru}_{0.2} \mathrm{Co}_{0.8}$. The shift of the $\mathrm{Co}_{3} \mathrm{O}_{4}$ peak to lower $2 \theta$ shows that $\mathrm{Co}_{3} \mathrm{O}_{4}$ lattice is expanded on addition of $\mathrm{Ru}$, with lattice parameter having increased from $8.079 \AA^{2}$ to $8.083 \AA$. Increase of the lattice parameter might be induced by substitution of $\mathrm{Ru}^{3 / 4+}$ into the octahedral sites of $\mathrm{Co}_{3} \mathrm{O}_{4}$ spinel. Ru can adopt several different oxidation states, -3 in the precursor $\left(\mathrm{RuCl}_{3}\right)$ or spinel type $\mathrm{Co}_{2} \mathrm{RuO}_{4}$ and +4 in $\mathrm{RuO}_{2}$ after oxidation during calcination. From the magnitude of the increase in lattice parameter we can conclude that not the complete $2 \%$ or $3 \%$ $\mathrm{Ru}$ addition have been substituted into the spinel

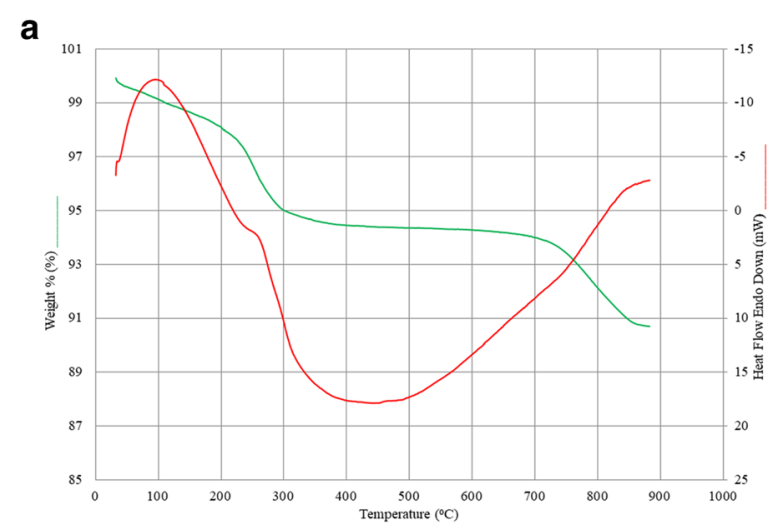

b

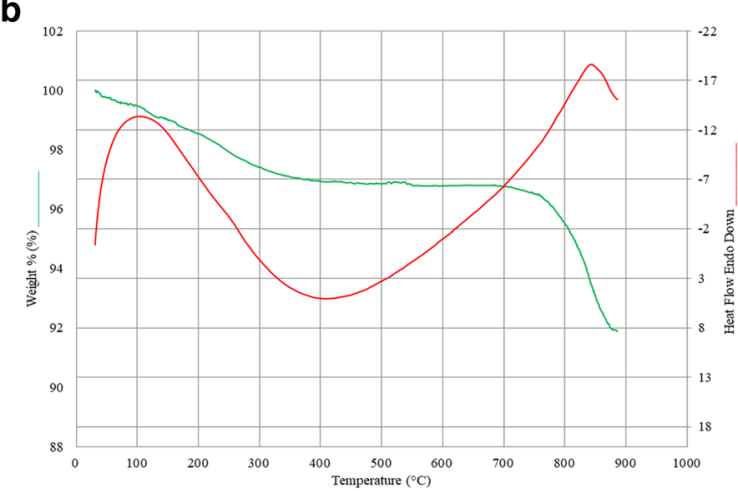

C

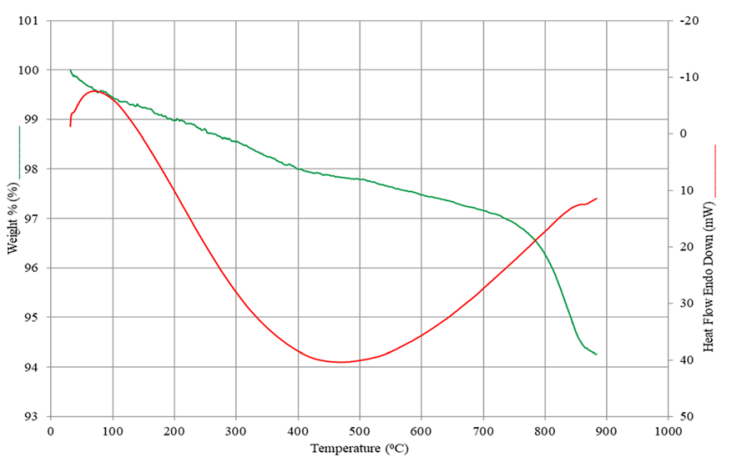

Fig. 3 TGA analysis of (a) $1 \%$, (b) $2 \%$ and (c) $3 \%$ Ru-Co bimetallic catalysts 




lattice. However, formation of $\mathrm{RuO}_{2}$, a form of low crystallinity or even amorphous and not detectable by $\mathrm{XRD}$, might be there.

After reduction No diffraction peaks corresponding to tetragonal rutile-type $\mathrm{RuO}_{2}$ could be seen in the reduced bimetallic $\mathrm{Ru}_{0.2} \mathrm{Co}_{0.8}$ and $\mathrm{Ru}_{0.3} \mathrm{Co}_{0.7}$ samples [Fig. 1 (c)] [34]. After reduction at $250^{\circ} \mathrm{C}$, the diffractions of $\mathrm{Co}_{3} \mathrm{O}_{4}$ for bimetallic Ru-Co samples disappear [Fig. 1 (c)]. The intensity of these peaks decreases with increasing Co content and almost disappears in $\mathrm{Ru}_{0.1} \mathrm{Co}_{0.9}$. The slight shift of $2 \theta$ value for $\mathrm{Ru}$ from $43.3^{\circ}$ for $\mathrm{Ru}_{0.3} \mathrm{Co}_{0} .7$ to $43.4^{\circ}$ in $\mathrm{Ru}_{0.1} \mathrm{Co}_{0.9}$ probably corresponded to a $\mathrm{Ru}$ phase that has some Co in the lattice $[35,36]$.

\section{SEM/EDX}

Surface morphology of these Ru-Co catalysts is visualized by Field Emission Scanning Electron Microscope (FE-SEM) [Make: JEOL, Model: JSM-7610F], which shows the magnified surfaces of 1,2 and $3 \%$ Ruthenium-Cobalt catalysts (see Fig. 2). EDX analysis of the three samples of $\mathrm{Ru}$-Co show the elements present in the catalysts with their weight and atomic percentages (see Table 2).
The presence of $\mathrm{Au}$ is associated with metallic coating of samples with gold for a clear surface morphology under FE-SEM [26]. The elements present in the catalysts are C (9.96-14.91 Wt.\%), O (10.69-31.96 Wt.\%), Co (50.21-67.46 Wt.\%), Ru (0.13-1.60 Wt.\%) and $\mathrm{Au}$ particles in the coating film (6.44-8.32 Wt.\%).

\section{TG/DTA}

Thermal stability of the Ru-Co catalysts is studied by Thermo-Gravimetric Analysis (TGA) [Make: PerkinElmer, Singapore, Model: Pyris Diamond TG/DTA], under nitrogen atmosphere (flow rate $=150 \mathrm{ml} / \mathrm{min}$ ). Platinum crucible is used with alpha alumina powder as the reference. TG/DTA results are shown in figures [Fig. 3 (a), (b), (c)] for the three different catalyst compositions.

The TG curves (green) show weight loss against temperature change for $\mathrm{Ru}$-Co catalysts of various compositions. It is clearly shown that catalysts containing less $\mathrm{Ru}$ encounter more weight loss than the ones with more $\mathrm{Ru}$. It is thus shown that catalysts containing larger percentage of $\mathrm{Ru}$ are more thermally stable during the entire time span of reaction. The average weight loss (\%) is in the order: $\mathrm{Ru}_{0.1} \mathrm{Co}_{0 \cdot 9}: 14.872>\mathrm{Ru}_{0.2} \mathrm{Co}_{0 \cdot 8}:: 9.894>$ $\mathrm{Ru}_{0.3} \mathrm{Co}_{0 \cdot 7}:: 8.117$. On the other hand, at $250{ }^{\circ} \mathrm{C}$



Fig. 5 Pathway B: Reaction route for the production of 1,4-butanediol and other byproducts 
Table 3 Design matrix of Box-Behnken Design data

\begin{tabular}{|c|c|c|c|c|}
\hline Run & Factor 1- A:Catalyst Concentration,\%Ru-Co & Factor 2- B:Temperature, ${ }^{\circ} \mathrm{C}$ & Factor 3- C:Pressure, Bar & $\begin{array}{l}\text { Response 1- } \\
\text { Yield of 1,4-BDO, \% }\end{array}$ \\
\hline 1 & 1 & 250 & 60 & 0.41 \\
\hline 2 & 1 & 180 & 60 & 0.26 \\
\hline 3 & 2 & 180 & 75 & 3.44 \\
\hline 4 & 3 & 250 & 60 & 5.01 \\
\hline 5 & 2 & 215 & 60 & 3.64 \\
\hline 6 & 2 & 250 & 75 & 3.67 \\
\hline 7 & 2 & 250 & 45 & 3.91 \\
\hline 8 & 2 & 215 & 60 & 4.69 \\
\hline 9 & 2 & 180 & 45 & 3.66 \\
\hline 10 & 2 & 215 & 60 & 4.09 \\
\hline 11 & 2 & 215 & 60 & 4.03 \\
\hline 12 & 3 & 215 & 45 & 4.38 \\
\hline 13 & 2 & 215 & 60 & 4.01 \\
\hline 14 & 3 & 215 & 75 & 5.03 \\
\hline 15 & 1 & 215 & 75 & 0.63 \\
\hline 16 & 3 & 180 & 60 & 4.63 \\
\hline 17 & 1 & 215 & 45 & 0.39 \\
\hline
\end{tabular}

(maximum temperature reached during high pressure hydrogenation) the weight loss (\%) is in the order:$\mathrm{Ru}_{0.1} \mathrm{Co}_{0 \cdot 9}:: 15.091>\mathrm{Ru}_{0.2} \mathrm{Co}_{0 \cdot 8}:: 9.964>\mathrm{Ru}_{0.3} \mathrm{Co}_{0 \cdot 7}:: 8.186$. This is probably because of an obvious carbon deposition over the catalysts (refer Table 2) during calcination. However the weight loss is not that prominent as reduction (following calcination) is strictly carried out under highly pure $\mathrm{H}_{2}$ atmosphere.

The DTA curves of the samples exhibited mostly endothermic peaks for the entire temperature regime. There is a prominent endothermic peak at approximately $270{ }^{\circ} \mathrm{C}$ for $\mathrm{Ru}_{0.1} \mathrm{Co}_{0.9}$ (could be assigned to the removal of adsorbed water) while the endothermic peak appears at around $460^{\circ}$ $\mathrm{C}$ in case of $\mathrm{Ru}_{0.3} \mathrm{Co}_{0.7}$. For $\mathrm{Ru}_{0.2} \mathrm{Co}_{0.8}$ however, a small endothermic peak appears at a much higher temperature, at around $835^{\circ} \mathrm{C}$. Here, $\mathrm{H}_{2}$ acted as a reductant to reduce the metal oxides to metallic $\mathrm{Co}$ and $\mathrm{Ru}$. $\mathrm{Ru}$ might have reduced first due to a low reduction temperature. The reduced $\mathrm{Ru}$ could act as a promoter to improve the reduction of Co. When the temperature is $>300{ }^{\circ} \mathrm{C}$ weight losses of the catalysts are found to be much smaller.

\section{Production of 1,4-butanediol}

It has been our primary objective to develop an efficient bimetallic catalyst to catalyze high pressure hydrogenation of bio-refined succinic acid (refer Fig. 4 Pathway A) in order to produce BDO. In the present work, only up to $6.04 \%$ BDO yield is achieved over a bimetallic $\mathrm{Ru}_{0.3} \mathrm{Co}_{0.7}$ catalyst while hydrogenating bio-based succinic acid under a high pressure of approximately 62 bar and $250{ }^{\circ} \mathrm{C}$.

The correlations between the catalyst structure and catalytic performance of the $\mathrm{Ru}-\mathrm{Co}$ catalysts with various Co contents are already discussed in the previous section. This is to have an idea on the probable active sites and reaction mechanism. After cyclization of succinic acid to GBL, ring-opening-hydrogenation to BDO takes up complex pathways. In Pathway $A$ [37], a C4 hemi-acetal analogue of 2-HTHP, 2hydroxytetrahydrofuran (2-HTHF), is likely to be formed by hydrogenation of GBL [38, 39].

Reduction capacity of $\mathrm{Co}$ is increased by a small amount of $\mathrm{Ru}(\sim 10 \mathrm{~mol} \%)$ in the bimetallic catalyst.

Table 4 Various models tested for the response

\begin{tabular}{lllll}
\hline Source & $\begin{array}{l}\text { Sequential } \\
p \text {-value }\end{array}$ & $\begin{array}{l}\text { Lack of Fit } \\
p \text {-value }\end{array}$ & $\begin{array}{l}\text { Adjusted } \\
\text { R-Squared }\end{array}$ & $\begin{array}{l}\text { Predicted } \\
\text { R-Squared }\end{array}$ \\
\hline Linear & $<0.0001$ & 0.0470 & 0.7723 & 0.6920 \\
$2 \mathrm{FI}$ & 0.9954 & 0.0247 & 0.7059 & 0.3849 \\
Quadratic & 0.0007 & 0.6334 & 0.9585 & $0.8876 \quad$ Suggested \\
Cubic & 0.6334 & & 0.9507 & Aliased \\
\hline
\end{tabular}


Table 5 Analysis of variance (ANOVA) for the response surface quadratic model

\begin{tabular}{|c|c|c|c|c|c|c|}
\hline Source & Sum of Squares & $\mathrm{df}$ & Mean Squares & F Value & $\begin{array}{l}\text { p-value } \\
\text { Prob }>F\end{array}$ & \\
\hline Model & 45.56 & 9 & 5.06 & 42.06 & $<0.0001$ & significant \\
\hline A-Catalyst Concentration & 37.67 & 1 & 37.67 & 312.94 & $<0.0001$ & \\
\hline B-Temperature & 0.13 & 1 & 0.13 & 1.06 & 0.3376 & \\
\hline C-Pressure & 0.023 & 1 & 0.023 & 0.19 & 0.6745 & \\
\hline$A B$ & 0.013 & 1 & 0.013 & 0.11 & 0.7500 & \\
\hline$A C$ & 0.042 & 1 & 0.042 & 0.35 & 0.5732 & \\
\hline$B C$ & $1.000 \mathrm{E}-004$ & 1 & $1.000 \mathrm{E}-004$ & 8.307E-004 & 0.9778 & \\
\hline$A \wedge 2$ & 6.99 & 1 & 6.99 & 58.07 & 0.0001 & \\
\hline$B \wedge 2$ & 0.22 & 1 & 0.22 & 1.79 & 0.2232 & \\
\hline$c \wedge 2$ & 0.16 & 1 & 0.16 & 1.34 & 0.2844 & \\
\hline Residual & 0.84 & 7 & 0.12 & & & \\
\hline Lack of Fit & 0.27 & 3 & 0.090 & 0.63 & 0.6334 & not significant \\
\hline Pure Error & 0.57 & 4 & 0.14 & & & \\
\hline Cor Total & 46.41 & 16 & & & & \\
\hline
\end{tabular}

This results in higher activity and selectivity of the catalyst. Several other mechanisms can also explain this process of hydrogenation to produce BDO. Considering Fig. 5 Pathway $B$ [37], GBL first gets hydrogenated to 2-HTHF, which then equilibrates with 4-HB (a ring-opened tautomer of 2-HTHF). A rapid hydrogenation to BDO over the metallic active sites follows thereafter. This reaction pathway is similar to the hydrogenation of 2-HTHP, the hemiacetal 2hydroxytetrahydropyran, to 1,5 pentanediol [40] and an analogous C6 route from tetrahydropyran-2 -methanol to 1,6-hexanediol [41].

\section{RSM-BBD modeling}

Using three numeric factors $\mathrm{BBD}$ is employed to determine the yield of 1,4-butanediol. Variation of numeric factors under different conditions are presented in Table 3.

The experimental data are fitted to various models like linear, 2FI, quadratic and cubic ones and compared in Table 4 and suitable statistical inferences are drawn.

After performing the ANOVA analysis (see Table 5), it is shown that the quadratic model is significant having a $p$-value lower than 0.0001 , a determination coefficient $R^{2}=0.982$, a value of the adjusted determination

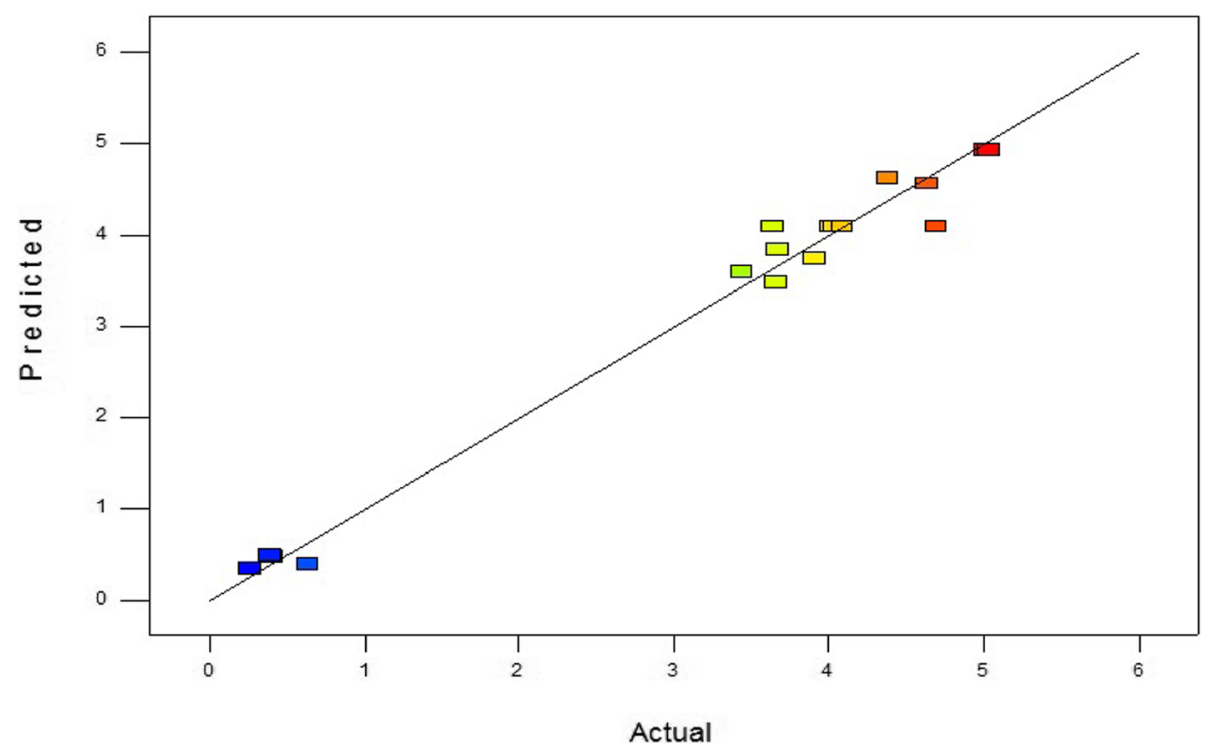

Fig. 6 Model predictions versus measured response, 1,4-Butanediol yield 
coefficient (adjusted $R^{2}$ ) $=0.959$ and a value of the coefficient of variation $(\mathrm{CV})=10.56 \%$.

he Lack of Fit is significant with a value of 0.63 and the second order polynomial eq. (2) represents the mathematical relationship between the response and the independent variables in the Box-Behnken experimental design.

$$
\begin{aligned}
\text { Yield } & =4.09+2.17 A+0.13 B+0.054 C+0.057 A B \\
& +0.1 A C-5.000 E-003 B C-1.29 A^{2}-0.23 B^{2}-0.2 C^{2}
\end{aligned}
$$

Using the developed model equations, experimental values are plotted against predicted values of yield in Fig. 6, indicating that the models are successful in capturing the correlation between the reaction parameters with respect to the response.
Influence of the process parameters on 1,4-butanediol yield The 3D graph (see Fig. 7) shows that the yield of 1,4-butanediol increases with the catalyst containing more ruthenium due to enhanced thermal stability of the same. The yield of butanediol is also maximized at the highest reaction temperature (see Fig. 7). In terms of pressure, it is clearly seen that the yield of butanediol increases if optimal stability pressure increases.

\section{Optimization of process parameters}

The high-pressure hydrogenation process is optimized to maximize 1,4-butanediol production yields utilizing bio-refined succinic acid using $\mathrm{Ru}-\mathrm{Co}$ bimetallic catalyst. In order to satisfy the optimum conditions of the process, all the process parameters, along with the response, are defined and given in Table 6 with their respective high and low limits. Following this, a new set of experiment is carried out using these optimized values.

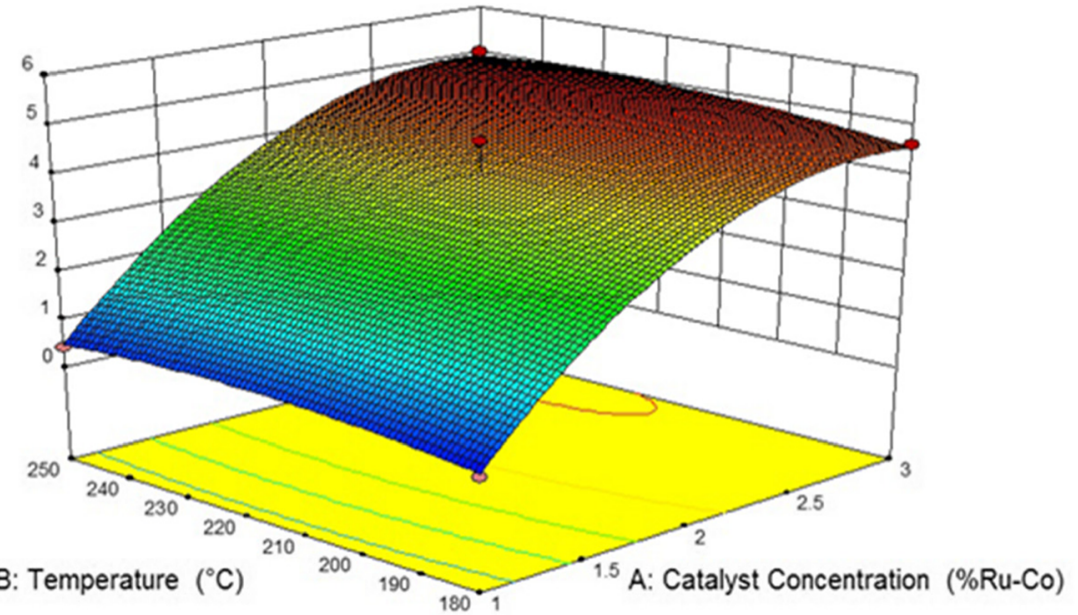

b

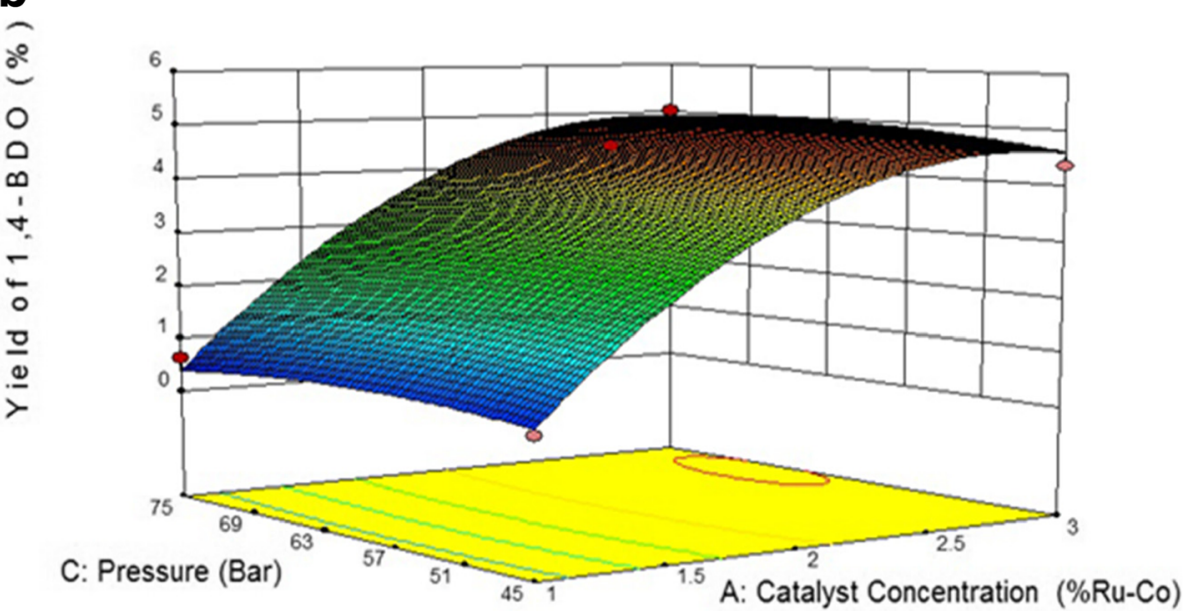

Fig. 7 3D Response surface plots showing the effect of various independent process variables on 1,4-Butanediol yield: (a) Effect of catalyst concentration and temperature on the yield of 1,4-Butanediol, (b) Effect of catalyst concentration and pressure on the yield of 1,4-Butanediol 
Table 6 Constraints for the factors and responses in numerical optimization

\begin{tabular}{llll}
\hline Parameter & Ultimate goal & \multicolumn{2}{c}{ Experimental region } \\
\cline { 3 - 4 } & & Lower limit & Upper limit \\
\hline Catalyst Concentration & In range & 1 & 3 \\
Temperature & In range & 180 & 250 \\
Pressure & In range & 45 & 75 \\
Yield of 1,4-BDO & Maximize & 0.26 & 5.03 \\
\hline
\end{tabular}

The optimum conditions generated by the statistical analysis are: catalyst concentration $=2.86 \mathrm{wt} \% \quad\left(=\mathrm{Ru}_{0.3} \mathrm{Co}_{0.7}\right)$, temperature $=235.65^{\circ} \mathrm{C}$ and pressure $=60.93$ bar with the optimum yield being $5.04 \%$, implying that under this optimum condition all the parameters of this statistical analysis gives its highest response. High pressure hydrogenation is conducted at these optimum conditions and the yield has been found to be approximately $6 \%$.

\section{Conclusions}

A series of $\mathrm{Ru}$-Co catalysts are prepared by an incipient wetness impregnation method. The prepared catalysts are applied for hydrogenation of succinic acid, already bio-refined using microbial fermentation of waste glycerol, to produce 1,4-butanediol under high pressure. The yield of 1,4-butanediol increased with the percentage of ruthenium present along with cobalt in $\mathrm{Ru}-\mathrm{Co}$ bimetallic catalysts. It is concluded that ruthenium-cobalt catalyst prepared by wet impregnation method can be a very effective catalyst towards the formation of 1,4-butanediol by high pressure hydrogenation of succinic acid. With bio-refined succinic acid as the starting material, the production of 1,4-butanediol under high pressure has been found to be cost-effective. In order to avoid the expensive process of purification of succinic acid from the fermentation broth, ultimately these derivatives could be produced directly in the fermentation broth if an optimally selective and active catalyst could be synthesized. It would also be a new challenge to overcome the inhibition scenarios that would arise while carrying out the catalytic production of the derivatives right within the fermentation broth. This could be so done since the hydrogenation reaction under high pressure could be carried out completely in gas phase under high pressure and all sorts of diffusional resistances (both film and pore) could be minimized.

\section{Endnotes}

${ }^{1}$ The Scherrer equation, in X-ray diffraction and crystallography, is a formula that relates the size of sub-micrometre particles, or crystallites, in a solid to the broadening of a peak in a diffraction pattern. It is named after Paul Scherrer. It is used in the determination of size of particles of crystals in the form of powder.
${ }^{2}$ Under common ambient conditions, the thermodynamically favored form of the cobalt oxide often is the normal spinel structure $\mathrm{Co}_{3} \mathrm{O}_{4}$ with a lattice constant $\mathrm{a}_{0}$ $=8.079 \AA$.

\section{Additional files}

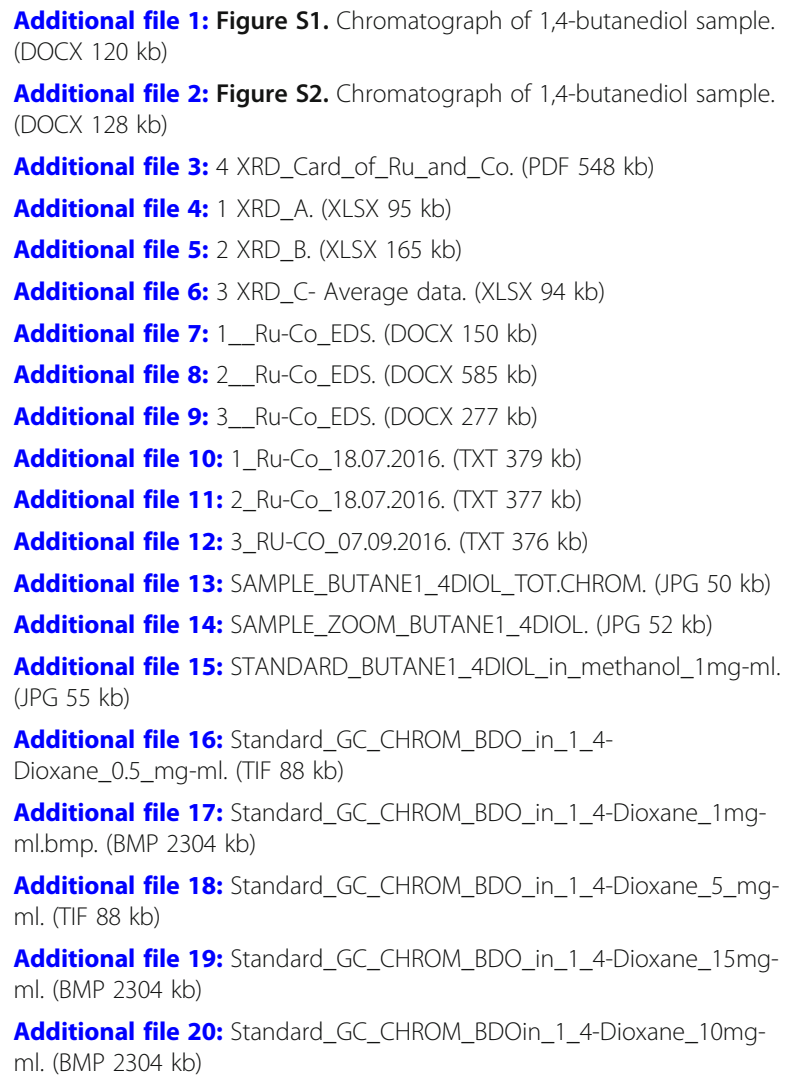

\section{Abbreviations}

2-HTHF: 2-hydroxytetrahydrofuran; 4-HB: 4-hydroxybutanal; ANOVA: Analysis of variance; BBD: Box-Behnken Design; BDO: 1,4-butanediol; FE-SEM: Field Emission Scanning Electron Microscope; GBL : Gamma-butyrolactone or $\gamma^{-}$ butyrolactone; GC-MS: Gas chromatography-Mass spectrometry; PBS: Polybutylene succinate; PBT: Polybutylene terephthalate; RSM: Response Surface Methodology; SA: Succinic acid; TGA: Thermogravimetric analysis; THF: Tetrahydrofuran; XRD: X-Ray Diffraction

\section{Acknowledgements}

The first author is particularly grateful to UGC, India under their Rajiv Gandhi National Fellowship for providing with a fellowship, consumables and chemicals. The authors also thank TCG Life sciences, Block BN, Plot 7, Salt-lake Electronics complex, Kolkata for giving permission to use their high pressure hydrogenation reactor for conducting hydrogenation experiments and Bose Institute, P 1/12, C.I.T. Road, Scheme-VIIM, Kolkata for conducting GCMS analysis.

\section{Funding}

The first author has received a research fellowship [F1-17.1/2015-16/RGNF2015-17-SC-WES-24832] from University Grants Commission (UGC), India under their Rajiv Gandhi National Fellowship (RGNF) programme throughout the period of study. The 'contingency' head was specifically utilized for collection, analysis and interpretation of data used to produce this manuscript. 


\section{Availability of data and materials}

All the relevant data, based on which this study has been carried out and utilized to produce the figures and tables embedded within the manuscript, are given as spreadsheet, text files etc. attached as Additional files 1, 2, 3, 4, $5,6,7,8,9,10,11,12,13,14,15,16,17,18,19,20$.

\section{Authors' contributions}

Mr. PKB: He has prepared the catalysts and carried out specific physical as well as chemical characterization. Further, he has helped in data acquisition while carrying out the experiments on high pressure hydrogenation. Prof US: Prof S has initiated a biorefinery with Crotalaria juncea as the feedstock, for the first time in India. She has helped in the completeness of this piece of research in terms of design of experiments, supplementing new ideas throughout, analysis and interpretation of the data. Dr RV: Dr. V has first designed the protocol for production of platform chemicals (Succinic acid, 1,3 propanediol, 1,4 butanediol etc.) using waste glycerol generated in a biorefinery for our research group. Based on her ideas we produced the bio-refined succinic acid. Dr SS: Dr. S has prepared the biorefined succinic acid, which has served as the raw material for high pressure hydrogenation. She has also helped us with the statistical analysis using Response Surface Methodology (RSM). All authors read and approved the final manuscript.

\section{Competing interests}

The authors declare that they have no competing interests.

\section{Publisher's Note}

Springer Nature remains neutral with regard to jurisdictional claims in published maps and institutional affiliations.

\section{Author details}

'Department of Chemical Engineering, Jadavpur University, Kolkata 700032, India. ${ }^{2}$ SWEE - School of Water, Energy and Environment, Cranfield University, Beds MK43 OAL, UK. ${ }^{3}$ Department of Chemical Engineering, Jadavpur University, Kolkata 700032, India.

\section{Received: 8 November 2018 Accepted: 27 February 2019}

\section{Published online: 24 April 2019}

\section{References}

1. Patel M, Crank M, Dornburg V, Hermann B, Roes A, Huesing B, et al. Medium and long-term opportunities and risks of the biotechnological production of bulk chemicals from renewable resources: UU CHEM NW\&S (Copernicus Institute of Sustainable Development, Utrecht, Netherlands); 2006.

2. Werpy T, Petersen G, Aden A, Bozell J, Holladay J, White J, et al. Top value added chemicals from biomass. Volume 1-results of screening for potential candidates from sugars and synthesis gas: U.S. Department of Energy, Washington DC, United States; 2004.

3. Okino S, Noburyu R, Suda M, Jojima T, Inui M, Yukawa H. An efficient succinic acid production process in a metabolically engineered Corynebacterium glutamicum strain. Appl Microbiol Biotechnol. 2008;81(3): 459-64.

4. Raab AM, Gebhardt G, Bolotina N, Weuster-Botz D, Lang C. Metabolic engineering of Saccharomyces cerevisiae for the biotechnological production of succinic acid. Metab Eng. 2010;12(6):518-25.

5. Song $\mathrm{H}$, Lee SY. Production of succinic acid by bacterial fermentation. Enzym Microb Technol. 2006;39(3):352-61.

6. Zeikus J, Jain M, Elankovan P. Biotechnology of succinic acid production and markets for derived industrial products. Appl Microbiol Biotechnol. 1999;51(5):545-52.

7. Kurzrock T, Weuster-Botz D. Recovery of succinic acid from fermentation broth. Biotechnol Lett. 2010;32(3):331-9.

8. Kurzrock T, Weuster-Botz D. New reactive extraction systems for separation of bio-succinic acid. Bioprocess Biosyst Eng. 2011;34(7):779-87.

9. Tooley PA, Black JR. Ru, Sn/oxide catalyst and process for hydrogenation in acidic aqueous solution: Patent No. US5985789A, United States; 1999.

10. Budge JR, Attig TG, Dubbert RA. Process for the hydrogenation of maleic acid to 1, 4-butanediol: Patent No. US6486367B1, United States; 2002.

11. Deshpande R, Buwa V, Rode C, Chaudhari R, Mills P. Tailoring of activity and selectivity using bimetallic catalyst in hydrogenation of succinic acid. Catal Commun. 2002;3(7):269-74.
12. Blanchet B, Morand K, Hulin A, Astier A. Capillary gas chromatographic determination of 1, 4-butanediol and $\gamma$-hydroxybutyrate in human plasma and urine. J Chromatogr B. 2002;769(2):221-6.

13. Chung S-H, Park Y-M, Kim M-S, Lee K-Y. The effect of textural properties on the hydrogenation of succinic acid using palladium incorporated mesoporous supports. Catal Today. 2012;185(1):205-10.

14. Hong UG, Park HW, Lee J, Hwang S, Yi J, Song IK. Hydrogenation of succinic acid to tetrahydrofuran (THF) over rhenium catalyst supported on $\mathrm{H} 2 \mathrm{SO} 4$ treated mesoporous carbon. Appl Catal A Gen. 2012;415:141-8.

15. Tapin B, Epron F, Especel C, Ly BK, Pinel C, Besson M. Influence of the re introduction method onto $\mathrm{Pd} / \mathrm{TiO} 2$ catalysts for the selective hydrogenation of succinic acid in aqueous-phase. Catal Today. 2014;235:127-33.

16. Hong UG, Park HW, Lee J, Hwang S, Song IK. Hydrogenation of succinic acid to $\gamma$-butyrolactone (GBL) over ruthenium catalyst supported on surfactanttemplated mesoporous carbon. J Ind Eng Chem. 2012;18(1):462-8.

17. Kang $\mathrm{KH}$, Hong UG, Jun JO, Song JH, Bang $Y$, Choi JH, et al. Hydrogenation of succinic acid to $\gamma$-butyrolactone and 1, 4-butanedio over mesoporous rhenium-copper-carbon composite catalyst. J Mol Catal A Chem. 2014:395:234-42.

18. Hong UG, Kim JK, Lee J, Lee JK, Song JH, Yi J, et al. Hydrogenation of succinic acid to tetrahydrofuran (THF) over ruthenium-carbon composite (Ru-C) catalyst. Appl Catal A Gen. 2014;469:466-71.

19. Hong UG, Hwang S, Seo JG, Lee J, Song IK. Hydrogenation of succinic acid to $\gamma$-butyrolactone (GBL) over palladium catalyst supported on alumina xerogel: effect of acid density of the catalyst. J Ind Eng Chem. 2011;17(2):316-20.

20. Dhakad M, Fino D, Rayalu S, Kumar R, Watanabe A, Haneda H, et al. Zirconia supported Ru-co bimetallic catalysts for diesel soot oxidation. Top Catal. 2007:42(1-4):273-6.

21. Bazin D, Kovacs I, Lynch J, Guczi L. Ru-co/NaY bimetallic catalysts: in situ EXAFS study at co K-and Ru K-absorption edges. Appl Catal A Gen. 2003; 242(1):179-86

22. Reinikainen M, Niemelä M, Kakuta N, Suhonen S. Characterisation and activity evaluation of silica supported cobalt and ruthenium catalysts. Appl Catal A Gen. 1998:174(1-2):61-75.

23. Dutta R, Sarkar U, Mukherjee A. Extraction of oil from crotalaria Juncea seeds in a modified Soxhlet apparatus: physical and chemical characterization of a prospective bio-fuel. Fuel. 2014;116:794-802.

24. Sadhukhan S, Sarkar U. Production of biodiesel from Crotalaria juncea (Sunn-hemp) oil using catalytic trans-esterification: process optimisation using a factorial and box-Behnken design. Waste and Biomass Valorization. 2016;7(2):343-55.

25. Sadhukhan S, Sarkar U. Production of purified glycerol using sequential desalination and extraction of crude glycerol obtained during transesterification of Crotalaria juncea oil. Energy Convers Manag. 2016;118:450-8.

26. Sadhukhan S, Villa R, Sarkar U. Microbial production of succinic acid using crude and purified glycerol from a Crotalaria juncea based biorefinery. Biotechnology Reports. 2016;10:84-93.

27. Kang KH, Hong UG, Bang Y, Choi JH, Kim JK, Lee JK, et al. Hydrogenation of succinic acid to 1, 4-butanediol over re-Ru bimetallic catalysts supported on mesoporous carbon. Appl Catal A Gen. 2015;490:153-62.

28. Shao Z, Li C, Di X, Xiao Z, Liang C. Aqueous-phase hydrogenation of succinic acid to $\gamma$-butyrolactone and tetrahydrofuran over $\mathrm{Pd} / \mathrm{C}$, re/C, and Pd-re/C catalysts. Ind Eng Chem Res. 2014:53(23):9638-45.

29. Chakraborty R, Bepari S, Banerjee A. Transesterification of soybean oil catalyzed by fly ash and egg shell derived solid catalysts. Chem Eng J. 2010; 165(3):798-805.

30. Ly BK, Minh DP, Pinel C, Besson M, Tapin B, Epron F, et al. Effect of addition mode of re in bimetallic $\mathrm{Pd}$-re/TiO2 catalysts upon the selective aqueousphase hydrogenation of succinic acid to 1, 4-butanediol. Top Catal. 2012; 55(7-10):466-73.

31. Hong UG, Lee J, Hwang S, Song IK. Hydrogenation of succinic acid to $\hat{I}^{3}$ Butyrolactone (GBL) over palladium-alumina composite catalyst prepared by a single-step sol-gel method. Catal Lett. 2011;141(2):332-8.

32. Tafreshi N, Sharifnia S, Dehaghi SM. Box-Behnken experimental design for optimization of ammonia photocatalytic degradation by ZnO/oak charcoal composite. Process Saf Environ Prot. 2017;106:203-10.

33. Talib NAA, Salam F, Yusof NA, Ahmad SAA, Sulaiman Y. Modeling and optimization of electrode modified with poly $(3,4-$ ethylenedioxythiophene)/graphene oxide composite by response surface methodology/box-Behnken design approach. J Electroanal Chem. 2017; 787:1-10. 
34. Wang J, Chernavskii PA, Khodakov AY, Wang Y. Structure and catalytic performance of alumina-supported copper-cobalt catalysts for carbon monoxide hydrogenation. J Catal. 2012;286:51-61.

35. Liu G, Pan D, Niu T, Cao A, Yue Y, Liu Y. Nanoparticles of Cu-co alloy supported on high surface area LaFeO 3-preparation and catalytic performance for higher alcohol synthesis from syngas. RSC Adv. 2015;5(40): 31637-47.

36. Xiao K, Qi X, Bao Z, Wang X, Zhong L, Fang K, et al. CuFe, CuCo and CuNi nanoparticles as catalysts for higher alcohol synthesis from syngas: a comparative study. Catalysis Science \& Technology. 2013;3(6):1591-602.

37. Huang Z, Barnett KJ, Chada JP, Brentzel ZJ, Xu Z, Dumesic JA, et al. Hydrogenation of $\mathrm{Y}$-butyrolactone to 1, 4-butanediol over $\mathrm{CuCO} / \mathrm{TiO} 2$ bimetallic catalysts. ACS Catal. 2017;7(12):8429-40.

38. Sun D, Sato S, Ueda W, Primo A, Garcia H, Corma A. Production of C4 and C5 alcohols from biomass-derived materials. Green Chem. 2016;18(9):2579-97.

39. Li F, Lu T, Chen B, Huang Z, Yuan G. Pt nanoparticles over TiO2-ZrO2 mixed oxide as multifunctional catalysts for an integrated conversion of furfural to 1, 4-butanediol. Appl Catal A Gen. 2014;478:252-8.

40. Barnett K, McClelland DJ, Huber GW. Autocatalytic hydration of Dihydropyran to 1, 5-Pentanediol precursors via in situ formation of liquidand solid-phase acids. ACS Sustain Chem Eng. 2017;5(11):10223-30.

41. Burt SP, Barnett KJ, McClelland DJ, Wolf P, Dumesic JA, Huber GW, et al. Production of 1, 6-hexanediol from tetrahydropyran-2-methanol by dehydration-hydration and hydrogenation. Green Chem. 2017;19(5):1390-8.

Ready to submit your research? Choose BMC and benefit from:

- fast, convenient online submission

- thorough peer review by experienced researchers in your field

- rapid publication on acceptance

- support for research data, including large and complex data types

- gold Open Access which fosters wider collaboration and increased citations

- maximum visibility for your research: over $100 \mathrm{M}$ website views per year

At $\mathrm{BMC}$, research is always in progress.

Learn more biomedcentral.com/submissions 